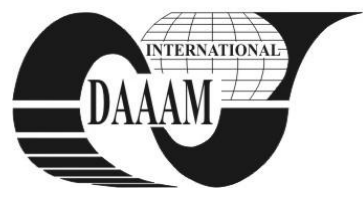

Annals of DAAAM for 2011 \& Proceedings of the 22nd International DAAAM Symposium, Volume 22, No. 1, ISSN 1726-9679 ISBN 978-3-901509-83-4, Editor B. Katalinic, Published by DAAAM International, Vienna, Austria, EU, 2011 Make Harmony between Technology and Nature, and Your Mind will Fly Free as a Bird Annals \& Proceedings of DAAAM International 2011

\title{
RELATIONSHIP BETWEEN TORQUES AND POWER CONSUMPTION IN DRY MACHINING OF UNS A92024-T3 ALLOY
}

\author{
DOMINGO, R[osario]; GARCIA, M[anuel] \& SEBASTIAN, M[iguel] A[ngel]
}

\begin{abstract}
This paper presents an experimental study about the effect of the torques on the calculation of the power consumption during the dry drilling in UNS A92024-T3 alloy. Thus, two drill types have been used with three different diameters. The coatings of nitrided lands and their impact on the power consumption during the dry drilling of aluminium alloy are analysed. In the tests have been utilised different cutting speeds and the power consumption has been calculated by a piezoelectric dynamometer, that allow obtaining the value of the thrust force and torques, once that the cutting speed has been fixed. Results provide information of the different degree of influence according the diameter of drill or the cutting length.
\end{abstract}

Key words: coatings, power consumption, dry machining, light alloys

\section{INTRODUCTION}

The dry machining processes have been studied under different perspectives because they are considered environmentally friendly process. Thus it recurrent to find analysis in which the cutting fluid is not present (Domingo et al., 2008; Domingo et al., 2009). However it is necessary to analyse more deeply the influence elements that allow increasing this sustainability, such as the coatings of cutting tools (Coldwell et al., 2004; Nouari et al., 2005) or cutting forces (Domingo et al., 2008) due to their influence on the power consumption. Nevertheless, these variables are researched under other perspectives, looking for outcomes, such as the thrust forces, the torques and more frequently the wear tool. There are a small number of studies focused on the process sustainability.

On the other hand, in the aeronautical field, the UNS A92024-T3 alloy is a material of special interest in the drilling process. Due to it, the behaviour knowledge has been analysed by different authors. For example, the evaluation of drilled hole quality (Kurt et al., 2008), some models to predict the thrust forces (Domingo et al., 2009), the optimization of cutting parameters for surface finish and hole diameter accuracy (Kurt et al., 2009). Once more, the sustainability continues without be present in the majority of the investigations. An important element of sustainability in manufacturing is the power consumption.

Thus, this paper presents a study about the effect of the torques on the power consumption during the drilling with drills without coating and with coatings of nitrided lands, considering different cutting conditions along the research study.

\section{EXPERIMENTAL METHODOLOGY}

The experimental methodology is focused on the taking of data from a piezoelectric dynamometer, in particular Kistler type 9257B. A correct configuration of this dynamometer allows obtaining the six variables, the three components of forces $(\mathrm{Fx}, \mathrm{Fy}$ and $\mathrm{Fz})$ and the three components of the torques $(\mathrm{Mx}, \mathrm{My}$ and Mz). Thus, the thrust force and the torque are found experimentally, during the drilling process in a milling CNC.

Almost, a multi-channel amplifier Kistler type 5070A has been used; the signals have been converted to units of forces and torques, by means of specific software DasyLab, programmed for this use, and to obtain mechanical data form electrical signals. In the Figure 1, the aluminium plates and the dynamometer can be observed.

The drills characteristics are shown in Table 1, they are two drills types, High Speed Steel twist (HSS) and High Speed Steel with nitrided lands twist (HSS N). Both drills types are recommended in aluminium alloy. They have different diameters, $4 \mathrm{~mm}, 6.3 \mathrm{~mm}$ and $8 \mathrm{~mm}$; thus six drills have been used, and 243 holes have been executed. Each tool has drilled a cutting length of $217.5 \mathrm{~mm}$ in UNS A92024-T3, according to thickness of plates. The cutting conditions are $\mathrm{N}=4000 \mathrm{rpm}$ and feed $\mathrm{f}=700 \mathrm{~mm} / \mathrm{min}$ for drills of diameters $4 \mathrm{~mm}$ and 6.3 $\mathrm{mm}$, and $\mathrm{N}=4000 \mathrm{rpm}$ and feed $\mathrm{f}=500 \mathrm{~mm} / \mathrm{min}$ for drill of diameter $8 \mathrm{~mm}$.

\section{RESULTS}

In this Section, firstly, the torques are shown. Afterward, the power is analysed, including the differences between the first hole and the average of results. Outcomes provided for torques are shown in Figure 2 and for power consumption in Figure 3.

It is possible to observe than in UNS A92024-T3 alloy, the drills more convenient, from a sustainable perspective are HSS, and the nitrided lands provoke a major consumption power. Although there is an exception for diameter $6.3 \mathrm{~mm}$ in the first hole; however the consumption power average for this diameter is more convenient also for HSS.

In Figure 4, the percentage attributed to torque in the power result is illustrated. In it, a high percentage is appreciated, superior to $94 \%$. Although there is difference between them, it is really much reduced. In the alloy UNS A92024-T3, the influence of torque is reduced for drill HSS and diameter $4 \mathrm{~mm}$ and drill HSS_N and diameter $6.3 \mathrm{~mm}$, during the average results front to first results drill.

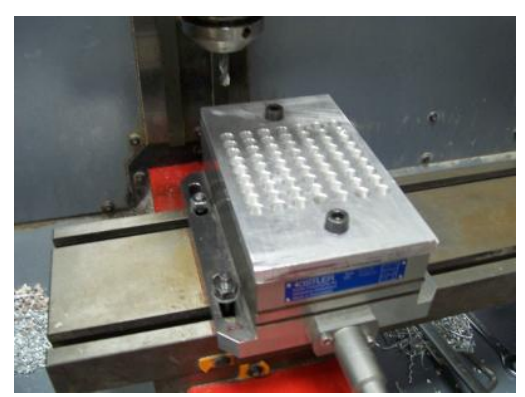

Fig. 1. Dynamometer and plate 


\begin{tabular}{|c|c|c|c|}
\hline Drill & Material & Coating & Point angle \\
\hline HSS & HSS & Bright & $130^{\circ}$ \\
\hline HSS N & HSS & Lands N & $130^{\circ}$ \\
\hline
\end{tabular}

Tab. 1. Drills type

In general, the calculation of the power of the first hole allows knowing the best drill under the minor consumption perspective. Only, an exception has been found, in UNS A92024-T3, for diameter $6.3 \mathrm{~mm}$.

A comparison between data from Figure 3 and Figure 4 permits to analyze the link between the percentages of torque on the power. As it can be seen, in UNS A92024-T3 the better conditions are reached by HSS drill with the lower cutting speed and the higher feed.

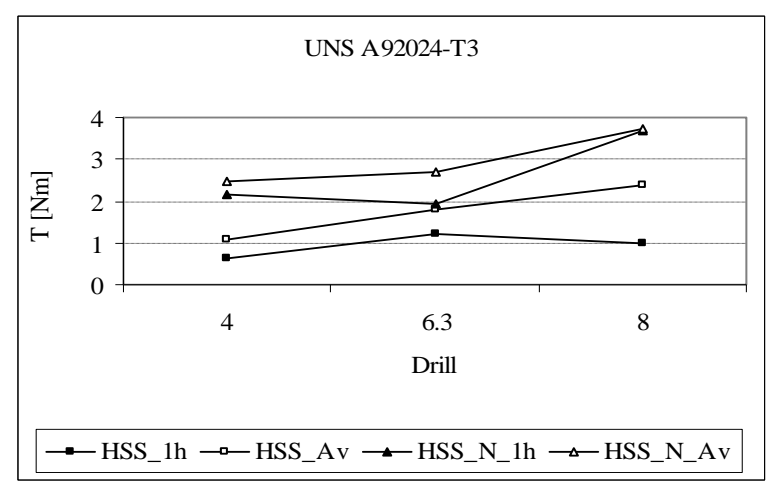

Fig. 2. Torque in UNS A92024-T3

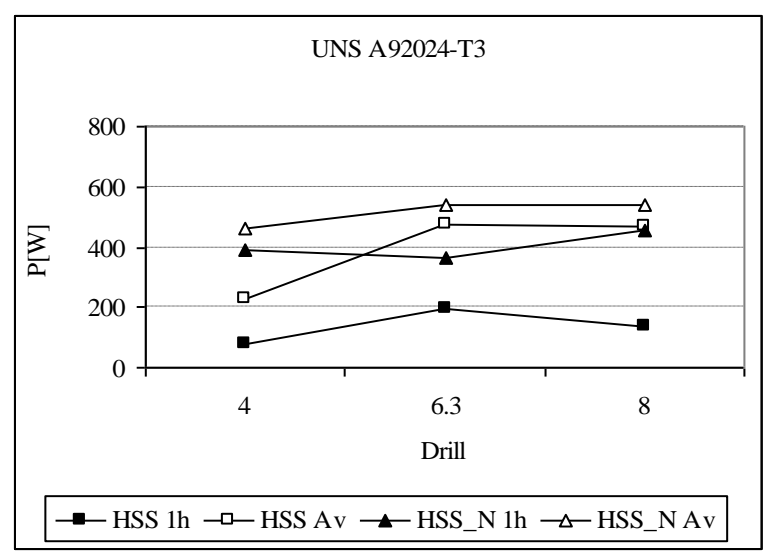

Fig. 3. Power consumption in UNS A92024-T3

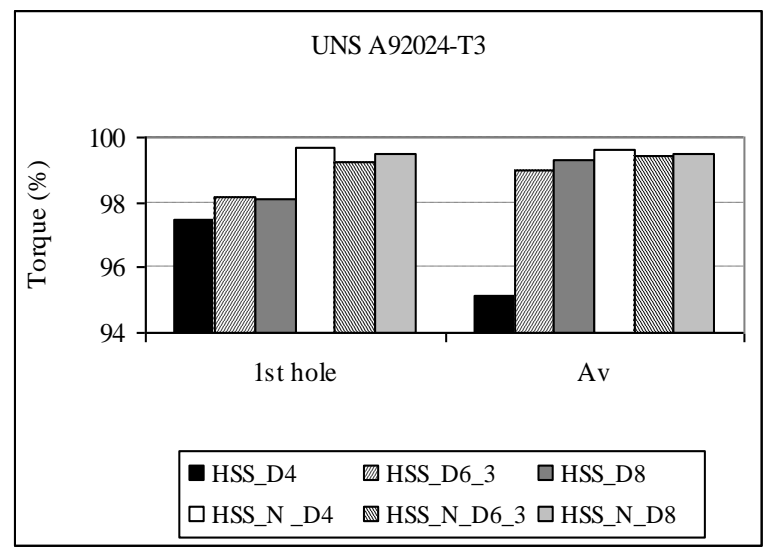

Fig. 4. Relationship between percentage of torque on the energy and roughness in UNS A92024-T3
In this sense, the feed seems to be an important variable to consider when the reduction of the power is an objective, although it is probably that the best cutting conditions were dependent of the type of drills, when the minimum power consumption was an aim.

This last question, it is maybe, the main limitation of this study, to know the dependency of the drills with the feed and speed in the determination of the power.

\section{CONCLUSIONS}

This paper has summarized the study carried out in order to know the influence the nitrided lands of the cutting tools on the power consumption during the dry machining of light alloys. Nowadays, the sustainable manufacturing is a priority and the consumption power should be analysed in the drilling processes, it necessary the calculation of torques. This paper has demonstrated that the influence of torque in the calculation of power consumption is superior to $94 \%$ when the drill is practically new. Also, the drill HSS provokes lower power consumption in UNS A92024-T3 than drill HSS_N as consequence of an increment of torque with the last drill.

In the future, a deeper study will be realized by the authors, analyzing the relationship between the energy and the wear tool, focused on different types of drills respect to materials, coatings and geometries, identifying the best cutting conditions for users of drills in industrial plants.

\section{ACKNOWLEDGEMENTS}

This work has received financial support from the MICINN (Spanish Government), by means of the project DPI200806771-C04-02.

\section{REFERENCES}

Coldwell, H.L., Dewes, R.C., Aspinwall, D.K., Renevier, N.M. \& Teer, D.G. (2004), The use of soft/lubricating coatings when dry drilling BS L168 aluminium alloy, Surface and Coatings Technology, Vol. 177-178, pp. 716-726, ISSN 0257-8972

Domingo, R., Alvarez, R., Rubio, E.M. \& Sebastian, M.A. (2008), Experimental analysis of cutting forces in dry drilling of UNS A92024 alloy, Journal of Machine Engineering, Vol. 8, No. 2, pp. 73-78, ISSN 1895-7595

Domingo, R., Alvarez, R. \& Sebastian, M.A. (2009) Prediction of Cutting Forces in the Dry machining of Lights Alloys Chapter 78 in DAAAM International Scientific Book 2009, B. Katalinic (Ed.), pp. 815-822, Published by DAAAM International, ISBN 978-3-901509-71-1, ISSN 1726-9687, Vienna, Austria

Kurt, M., Bagci, E. \& Kaynak, Y. (2009), Application of Taguchi methods in the optimization of cutting parameters for surface finish and hole diameter accuracy in dry drilling processes, International Journal of Advanced Manufacturing Technology, Vol. 40, pp. 458-469, ISNN 0268-3768

Kurt, M.; Kaynak, Y. \& Bagci, E., (2008), Evaluation of drilled hole quality in Al 2024 alloy, International Journal of Advanced Manufacturing Technology, Vol. 37, No. 11-12, pp. 1051-1060, ISSN 0268-3768

Nouari, M., List, G., Girot, F. \& Gehin, D. (2005), Effect of machining parameters and coating on wear mechanisms in dry drilling of aluminium alloys, International Journal of Machine Tools \& Manufacture, Vol. 45, pp. 1436-1442, ISSN 0890-6955 